\title{
The Reflection and Construction on the Research Methods of Science of
}

\section{Criminal Investigation}

\section{Zhang Xin}

School of Law of Wuhan University, Wuhan 430072 Hubei

Abstract: The science of investigation is a discipline on the countermeasure application and has a crucial role in the criminal investigation activity. The research of science of investigation has been carried out since the establishment of People's Republic of China. In the process of long-term study and discussion, people have gradually enriched and perfected the investigation means, improved the detection efficiency on the criminal offense, and effectively safeguarded the social stability and harmony. At present, although the research achievement and methods related to the criminal investigation are more significant and practical, the research methods of criminal investigation should still be further improved and optimized for more complex criminal cases in order to constantly adapt to new requirements and environment of investigation activities.

Keywords: Science of Investigation, Research System, Research Method

\section{INTRODUCTION}

Science of Investigation is an important support of modern criminal investigation activity, and the application of criminal investigation allows investigators to further accurately and quickly identify the motive for criminal offenses as well as the collection of the criminal evidences, which plays a very important role in the arrest of the criminal suspect. Currently, with the continuous development of society and the growing diversity in criminal cases, the study on criminal investigation has gradually accessed into the confused stage. How to build the innovative evaluation criteria of research on criminal investigation and determine more scientific and practical research methods have become the important issues to be solved in the research of criminal investigation.

\section{Discipline Attribute of}

Science of Criminal Investigation

As an independent discipline in China, the science of criminal investigation shall have the perfect and independent organizational systems of discipline, but the criminal investigation in China still has not been formed its own independent study in the process of actual research and analysis, and there often exist the major conflicts and overlap compared with other disciplines, which undoubtedly makes the status of the criminal investigation been questioned.

\section{(1) Relationship between Criminal}

Investigation and Law Science. Since there are major consistency and similarity between many research contents of criminal investigation and law science, a lot of research works can be smoothly developed with the help of the theories and thoughts of law science. Therefore, most of experts and scholars have suggested the criminal investigation to be classified as the branch of law science. Although there exist higher similarity between parts of research objects of criminal investigation and law science, the contents contained in the criminal investigation can't be covered in law science, 
many study contents of criminal investigation are required under the support of physics, computer science, communication technology, medicine and other disciplines, which are beyond the scope of the study of law.

\section{(2) Relationship between Criminal} Investigation and Public Security. Public Security is the research system mainly aiming to the rules and countermeasures of public security works in China, the general terms of public security discipline, and the interdiscipline of social science and natural sciences. Over the years, the public security science and the law science have all been regarded as the important first-level disciplines, which has very important research value and significance, while the criminal investigation science has been listed into second-level discipline. Similarly, there is major interaction on the research between the criminal investigation science and the public security science, most researches on the criminal investigation shall be completed depending on the public security, and the study objects of the criminal investigation also have greater relevance with those of the public security science. However, the criminal investigation blindly incorporated into the theory of the public security will cause the application scope of criminal investigation to be bound, and the actual value of the criminal investigation will be greatly reduced.

\section{(3) Relationship between Criminal} Investigation and Criminology. The criminal investigation has an extremely important significance on the detection of criminal cases. With the support of criminal investigation, investigators can more quickly recognize the motive to the crime, identify the perpetrators of crime, and promote more rapid detection of cases. Since the main application field for the criminal investigation science is the criminal investigation, some experts and scholars believe that the investigation science should be incorporated into the criminology. Although research achievement of investigation science has been shown in the investigation of criminal cases and the large number of crimes has been involved in the researches, but the application scope of investigation science is not limited to this, and the emphasis is on the preparation of investigation countermeasures, not the breakthrough and prevention of problems.

\section{(4) Relationship between Criminal} Investigation and Criminal Science. The criminal science is the concept of unified discipline formed for the criminal offence. The concept of criminal science has been formed for a long time, and some researchers have attempted to integrate the integration science, criminology, criminal law and criminal procedure as a relatively complete criminal discipline in order to carry out the relevant study. Although the combination of disciplines with higher similarity seemingly can effectively improve the research quality and level, the research objects will be not effectively selected and the construction of research system will face a more complicated situation due to higher independence between various disciplines and different characteristics of disciplines.

III. Tridimensional, Open and

\section{Dynamic Elements of Criminal Investigation System}

(1) Tridimensional Element of Criminal Investigation Theory. The criminal investigation as an important application discipline with countermeasures, is the important theoretical basis for the investigation activities. Since the main application field of the criminal investigation science is the criminal investigation, the three-dimensional theories and thoughts should be emphasized in order to 
achieve the expansion and extension in thoughts and make further in-depth study on the investigation issues. Actually, the narrow limitation of thoughts are excluded in the criminal investigation science due to the complex and various criminal cases. The minor parts in the cases will directly determine the hearing efficiency of the cases, and the analysis and investigative thoughts with the application of more points, lines, surfaces and three-dimensional style can better break the constraints of time and space.

(2) Openness of Criminal Investigation System. As mentioned above, the criminal investigation is mainly based on the preparation of countermeasures, and the investigation system emphasizes on the comprehensive knowledge, which can ensure the order implementation of the clues collection, information acquisition, strategy formulation and other activities in order to effectively promote the detection of criminal cases. Therefore, the openness of the system is required to further maintain without limit of some scientific knowledge and research theories in the criminal investigation system. For example, in the process of many cases investigation, the evidence of a crime should be learnt firstly from the aspects of physical evidence, physics, legal medicine and law, and then the evidence should be searched from the change of perspectives and thoughts, the aspects of physics, chemistry even the IT to achieve the breakthrough on the investigation activities when the study in a chaotic situation.

(3) Dynamics of Criminal Investigation System. The higher dynamics should be kept for the criminal investigation system for the theoretical knowledge shall be referred and used on the formulation of countermeasures in the criminal investigation, but over-reliance on theoretical knowledge in writing will make the investigation activities fallen into the standstill, and the blindly still research activities will facilitate the investigation becoming more lag. Therefore, the dynamics of investigation and countermeasures are required to be emphasized, the organic integration of investigation means are be made with use of the scientific and rational mode, the investigation countermeasures shall be continuously improved and optimized and the effectiveness of countermeasures shall be adjusted to promote the actual effect of countermeasure investigation according to the improvement of research on the cases. With the gradual development of society and the gradual improvement of anti-investigation awareness of criminal offenders, the investigation activities are repeatedly led into deadlock, and then the dynamics of the system should be further supported and the static problems should be solved based on the dynamic thoughts, rather than sit back and wait or enjoy.

IV.

Issues existed in Research on

\section{Criminal Investigation}

(1) Embarrassed Double Positions in Research on Criminal Investigation. The exploration and study of any matters is a complex process, and the right attitude must be had in the process. Thus, the ideas and determinations to be insisted to judge if true or false can eliminate the fictitious factors and identification barriers that existed in objects to ultimately explore the essences of things. Meanwhile, an observation point should be made for the decision to explore for the things, and the basic vision and direction can be measured and judged through the observation point. If the observation point is in chaos, the confusion and complexity of the inquiry process will be caused and more logical contradictions 
and difficulties will be finally resulted in the exploration of matters.

While in the process of the research on the criminal investigation, there exists this kind of contradiction in the setup of observation point. Under the influence of dual positions, the study on the criminal investigation will be ultimately resulted into the awkward contradiction on research and the single blindness. At present, for the position and orientation of criminal investigation, some experts and scholars tend to regard it as the auxiliaries to the research of litigation law, and believe that the criminal investigation only pays a role in the investigation in the process of proceedings. On the basis of this view and understanding, the criminal investigation is often easy to fall into the embarrassed dual positions. Due to the fuzzy positioning of the criminal investigation, the investigation will often pay too much emphasis on the pursuit of procedures and rules during the actual application, while ignoring the truth of the investigation results and ultimately leading the investigation into the strange cycle against the truth.

(2) Marginality and Marginalization incurred in Criminal Investigation. Although the criminal investigation plays extremely important role in solving the criminal offence issues, the actual situation of the investigation is very embarrassed. Currently, the criminal investigation is a kindly of auxiliary discipline and shows the over-marginalization compared with criminology, law and other disciplines. Generally, the criminal investigation simply plays a synergistic role during the process of criminal cases investigation, such as the cases detected under the support of criminology or the cases hearing together with the procedural law, which cause the limitations on the application of criminal investigation. Most experts and scholars believe that the criminal investigation just is one procedure in the criminal proceedings and is auxiliary to the research on procedural law, as well as hasn't any value for itself. At present, it is common for above views and opinions existed. As a result, the research on the criminal investigation encounters greater cold reception and patterns, the researchers engaged in the criminal investigation take up the researches on other subjects and projects, and thus the study on the criminal investigation is severely restricted.

(3) The Matthew Effect in Research on Criminal Investigation. At present, the actual study implemented on law, procedural law, criminal psychology and other disciplines is very thorough, the rich research data and documents can be found in domestic, and the considerable academic strength can be used in the process of research, which effectively guarantees the efficiency and quality of researches. However, it is not optimistic for the current situation of research on the criminal investigation reviewed, and the study of the investigation falls into the Matthew effect due to the positioning. Currently, the literatures related to the study of the criminal investigation at home and abroad are very limited, the relevant data is usually mingled with other scientific information, and the study on the criminal investigation independently implemented is few. Due to the pressure, many researchers of the criminal investigation often can only go against their own will and original intention to carry out the research in the field of law in order to avoid the obstacles in the research on the criminal investigation.

V.

Construction on the Research Methods of Criminal Investigation

The research of criminal investigation is actually requested by the modern criminal cases 
investigation and objectively required for the complication and diversity. For the construction on the research methods of criminal investigation, the independent status of the investigation should be firstly established in order to ensure the study related to the investigation can be freely and independently carried out, the core of the study of the investigation should be defined, and the correct research attitude on the criminal investigation shall be set up.

\section{(1) Focus in Research on Criminal Investigation}

A. "Truth, Goodness and Beauty" of Investigation. The "Truth, Goodness and Beauty" of investigation should be cared for the research of the criminal investigation in order to ensure the research of the investigation becoming more rational and scientific. Truth, which is to emphasize the objectiveness and authenticity of the investigation results and explore the existence of the facts. The purpose of criminal investigation activity is mainly to seek the real situation and the investigation task is to restore the truth. The implementation of the investigation activity aims at restoring the truth of cases, seeking the reasons of cases happened, and learning about the process of cases and the motive for the crime. The investigation activity should only have itself concepts if the truth of investigation results can't be ensured. Goodness, which refers to the implementation of investigation activity based on the pursuit of truth as a starting point, the investigation activity shouldn't be subject to the limitation of other factors, and the truth of investigation results shall not be influenced by the subjective factors according to the just features and the fair principles. Beauty, which means the excellent investigation wisdom. The implementation of investigation activity actually is the comparison on the wisdom. Generally, the criminal offenders will create a lot of false scent after commit a crime to impact the investigation results on the cases. While the criminal investigation is to solve various difficulties and obstacles correspondingly, and to acquire the truth depending on the wisdom. Science of Criminal Investigation

\section{B. Focus in Research on Criminal} Investigation. The research focus of criminal investigation is to aim at how to better apply the criminal investigation to complete the investigation activity of criminal cases after adopt the scientific and effective investigation means for different cases. Essentially, the research of criminal investigation is to make study for the investigation technology and methods. With the continuous development of science and technology, a large number of invention of advanced investigation technology has great support on investigation activities and enhances the efficiency and level of investigation. However, investigators should manage the investigation means and formulate the investigation plans and countermeasures before the implementation of investigation activities, so as to avoid the blindness of detection behavior. Therefore, for the research on the criminal investigation, we should devote more efforts to the study on the investigation process and strategy, emphasize the construction of investigation thoughts and the standards of investigation plans, and strengthen the coordination of investigation technology and equipment on the corresponding basis in order to improve the investigation quality and results. Meanwhile, with the improvement of criminal offender's knowledge, the anti-detection capability is more and more strong. Therefore, the principle of keeping up with the time should also be emphasized in the research of criminal 
investigation. While paying attention to the analysis and research on the traditional cases, strengthening the update and richness of research cases, summarizing the difficulties and emphasis through the analysis and inquiry of the special cases, implementing the discussion and analysis for these issues to review and summarize issues, propose the specific methods to deal with the problems, and ultimately uncover the truth of the cases.

\section{(2) Attitude in Research on Criminal Investigation}

A. Awareness of Reality and Rationality. From the point of view of procedural law, the investigation just is the procedural requirements in the process of criminal cases investigation and trial. But from the role and significance of the investigation activities, the investigation is the irreplaceable key during the investigation procedure. With the continuous development of society and the promotion of the people's consciousness rights, the criminal investigation procedures in China have conducted greater reform and the legitimate interests of suspects have been better maintained. As a result, the case hearing becomes more complex, and the detection difficulty of the cases increasingly becomes more difficult. Based on the complex investigation situations, the research on the criminal investigation should also be conducted the corresponding change. For the research of criminal investigation, the feasibility of investigation should be better emphasized, in addition to the emphasis on study of the investigation strategy and means. At the same time, the contradiction between the police and the people should be relieved and the efficiency and level of investigation should also be guaranteed. Therefore, the social conflicts and the negative impacts caused in the process of investigation should be properly reduced and controlled when the investigation results are concerned.

\section{B. Tolerance on Efficiency of Investigation.} Using the criminal investigation to implement the investigation activities, which is the important means to improve the investigation efficiency of criminal cases, but the criminal investigation is not universal and the investigation results possibly are not ideal due to the differences between the cases natures and the criminal offender level. From an objective point of view, the criminal offender can escape by a number of channels after the criminals engaged in the criminal activity, but the investigators can only implement investigation and trace along the path which the suspected criminals escaping from. Thus, the detection difficulty is unimagined. At the present stage, with the accelerating pace of social development, the number of crimes has risen, people are more inclined to measure the actual ability and level of the investigator based on the detection efficiency. If blindly study the standard of cases detection rate and simply pursue the high detection rate, it goes against the perfection of investigation means and program design, but also easy to hasten the tortures and other illegal acts. Therefore, the criminal investigation should be studied on the basis of calmness and objectiveness. When high expectations are estimated for the criminal investigation, we should give it sufficient tolerance and trust, objectively analyze the issues existed in the investigation activities, and use the scientific cognition and theory to guide the investigation and practice.

\section{Conclusions:}

The criminal investigation is as the important application discipline. For the research on the criminal investigation, the investigator should keep the positive attitude and adhere to the 
scientific principles to pursue the truth as the basic starting point of the research on the criminal investigation. Currently, the research on the criminal investigation encounters greater difficulties, and the issues on the positioning of the criminal investigation causes the great constrains on the study of the investigation. Therefore, we should well conduct the positioning of the criminal investigation, regard the investigation as the independent research discipline, strengthen the innovation on the investigation strategies and methods to break the bottleneck of traditional research, and improve the actual role and value of the criminal investigation with an open, dynamic and three-dimensional study.

\section{References:}

[1] Jiang Yong. Philosophical Reflection on the Research of Criminal Investigation [J]. Journal of People's Public Security University of China (Social Science Edition), 2013 (06): 83-90.

[2] Chen Wengao. Discussion on the Research Methods of Criminal Investigation - Discussion with "The Reflection and Reconstruction on the System of Criminal Investigation" [J]. Journal of People's Public Security University of China (Social Science Edition), 2011, 27 (02): 21-25.

[3] Lin Weiye. Study on Innovation of Investigation Methods [J]. Journal of Beijing People's Police College, 2009 (06).

[4] Guo Bing. Standardization Construction and Information Construction on Enforcement and Investigation - Summary of the Second Symposium on Investigation Behavior Seminar of Chinese Behavior Law [J]. Journal of National Prosecutors College, 2010 (01): 136-141.

[5] Yang Zonghui, Liu Weijun. Investigative Methodology [M]. Procuratorial Press of China, 2004.

[6] Liang Wubin. The Reflection and
Reconstruction on the System of Criminal Investigation [J]. Journal of People's Public Security University of China (Social Science Edition), 2010 (05): 80-89.

[7] Fan Wei. Restudy on Criminal Case Investigation and Field Investigation Methods The Second New Thought on Research Methods of Criminal Investigation [J]. Journal of Puyang Vocational and Technical College, 2013, 26 (03): 14-16.

[8] Fan Wei. The Research of Criminal Case Investigation and Field Investigation Methods The New Thought on Research Methods of Criminal Investigation [J]. Citizenship and Law (Law Edition), 2013 (3). 